\title{
TINJAUAN KRITIS KONTRIBUSI PENELITIAN DALAM MENINGKATKAN DAYA SAING ORGANISASI POLITEKNIK
}

\author{
Iis Mariam ${ }^{1)}$, Endah Wartiningsih ${ }^{2)}$ dan Nining Latianingsih ${ }^{3)}$ \\ Staf Pengajar Jurusan Administrasi Niaga, Politeknik Negeri Jakarta, \\ Kampus Baru UI, Depok \\ Email: 1 iis.mariam@yahoo.com ,2endah.wartiningsih@gmail.com, ${ }^{3}$ nilaahen@yahoo.co.id
}

\begin{abstract}
Abstrak
Pola pendidikan tinggi saat ini didorong untuk lebih inovatif dalam upaya membantu pemerintah mewujudkan peningkatan kualitas sumber daya manusia yang handal dan profesional dalam memenuhi kebutuhan industri dan perusahaan sehingga memiliki nilai daya saing organisasi yang tinggi. Salah satu faktor yang berkontribusi pada peningkatan daya saing organisasi adalah kemampuan dosen dalam melakukan salah satu bagian dari Tri Dharma Perguruan Tinggi yaitu melakukan penelitian dan pengabdian pada masyarakat. Faktanya, keterlibatan dosen PNJ. Perguruan tinggi dituntut untuk mampu mendorong dosen melakukan penelitian dalam melakukan penelitian masih belum berorientasi pada HAKI dan belum berdampak secara ekonomis. Merujuk pada UU.Nomor 12 Tahun 2012 tentang PT, Permendikbud Nomor 49 Tahun 2014 tentang SN Dikti dan Permenristek Dikti Nomor 44 Tahun 2015 tentang SNPT, sangat jelas disebutkan bahwa setiap perguruan tinggi harus dapat mengelola kegiatan penelitian merujuk pada standar nasional penelitian yang meliputi delapan standar, yaitu: hasil penelitian, isi penelitian, proses penelitian, penilaian penelitian, peneliti/pelaksana, sarana dan prasarana penelitian, pengelolaan penelitian, dan pendanaan dan pembiayaan penelitian. Masalah yang muncul selain keterlibatan dosen dalam penelitian adalah faktor apakah dari keempat aspek berikut: sumber daya, manajemen, luaran dan revenue generating yang sudah dilakukan dan berkontribusi dalam peningkatan daya saing organisasi politeknik? Apakah dosen PNJ telah melakukan penelitian yang berorientasi pada penciptaan inovasi teknologi dan pengembangan usaha masyarakat. Metode yang dilakukan dalam penelitian ini adalah deskriptif kualitatif dengan teknik pengumpulan data menggunakan studi literature, partisipative observation dan wawancara.
\end{abstract}

Kata Kunci: penerapan waktu kerja lembur, UU No 13 Tahun 2013 tentang Tenaga Kerja, lulusan baru, perusahaan konstruksi

\section{PENDAHULUAN}

Dalam era globalisasi saat ini dan perkembangan teknologi informasi yang demikian cepat, berdampak pada penyelenggaraan pendidikan tinggi sebagai salah satu pilar dan wadah untuk menghasilkan sumber daya manusia yang cerdas, kreatif dan inovatif sesuai dengan kebutuhan industri. Pendidikan tinggi memiliki tri dharma perguruan tinggi, dimana dosen harus memiliki kemampuan tidak hanya mengajar tetapi juga meneliti dan melakukan pengabdian pada masyarakat. Merujuk pada kondisi tersebut, peran dan kontribusi dosen dalam melakukan tri dharma menjadi suatu modal kolaborasi antara pendidikan dengan masyarakat, pemerinath serta industri. Oleh karena itu, kiprah dosen dalam melakukan penelitian menjadi faktor penting yang harus diperhatikan agar mampu menghasilkan penelitian yang kreatif, inovatif sehingga mampu memperkuat daya saing organisasi, berdampak pada peningkatkan ekonomi serta memiliki potensi HAKI. Penelitian di Politeknik bercirikan penelitian terapan dan sesuai dengan kebutuhan lingkungan saat ini yang bergerak secara turbulen merujuk pada rencana induk riset nasional (RIRN) yang merupakan riset pada tingkat nasional dan menjadi prioritas dalam program pemerintah. 


\section{Tinjauan Pustaka \\ Pengertian Penelitian}

Pengabdian kepada Masyarakat, adalah kegiatan yang berorientasi pada pelayanan masyarakat dan penerapan ilmu pengetahuan teknologi dan seni terutama dalam menyelesaikan permasalahan masyarakat dan memajukan kesejahteraan bangsa. Menurut Peraturan Menteri Pendidikan dan Kebudayaan Republik Indonesia Nomor 49 Tahun 2014 Tentang Standar Nasional Pendidikan Tinggi (SN DIKTI), yang kemudian dikuatkan kembali melalui Peraturan Menteri Riset, Teknologi dan Pendidikan Tinggi Nomor 44 Tahun 2015 tentang Standar Nasional Pendidikan Tinggi, dalam Bab I Ketentuan Umum pada pasal 1 dinyatakan bahwa Standar Nasional Pendidikan Tinggi adalah satuan standar yang meliputi Standar Nasional Pendidikan, ditambah dengan Standar Nasional Penelitian, dan Standar Nasional Pengabdian kepada Masyarakat.

\section{Tujuan Program Penelitian}

1. menghasilkan penelitian yang sesuai dengan prioritas nasional yang ditetapkan oleh Pemerintah dan mengacu pada Permenristekdikti Nomor 13 Tahun 2015 Tentang Rencana Strategis Kementerian Riset, Teknologi, dan Pendidikan Tinggi Tahun 20152019;

2. menjamin pengembangan penelitian unggulan spesifik berdasarkan keunggulan komparatif dan kompetitif;

3. mencapai dan meningkatkan mutu sesuai target dan relevansi hasil penelitian bagi masyarakat Indonesia; dan

4. meningkatkan diseminasi hasil penelitian dan perlindungan kekayaan intelektual secara nasional dan internasional

\section{Aspek Yang Dinilai Dalam Kinerja Penelitian}

Salah satu usaha yang perlu dilakukan adalah melakukan evaluasi melalui penilaian kinerja penelitian mencakup aspek: 1) artikel ilmiah dimuat di jurnal, 2) artikel ilmiah dimuat di prosiding, 3) (keynote speaker/invited) dalam temu ilmiah, 4) pembicara kunci/tamu (visiting lecturer), 5) hak kekayaan intelektual (HKI), 6) teknologi tepat guna, 7) model / purwarupa / desain / karya senin / rekayasa sosial, 8) buku (ISBN), 9) jumlah dana kerja sama penelitian, dan 10) angka partisipasi dosen.

\section{Strategi Dalam Organisasi}

Merujuk pada visi Kementerian Riset, Teknologi, dan Pendidikan Tinggi yang telah menetapkan visi tahun 2015-2019, yaitu: “Terwujudnya pendidikan tinggi yang bermutu serta kemampuan iptek dan inovasi untuk mendukung daya saing bangsa” Pendidikan tinggi yang bermutu dimaksudkan untuk menghasilkan lulusan yang berpengetahuan, terdidik, dan terampil, sedangkan kemampuan iptek dan inovasi dimaknai oleh keahlian SDM dan lembaga litbang serta perguruan tinggi dalam melaksanakan kegiatan penelitian, pengembangan, dan penerapan iptek yang ditunjang oleh penguatan kelembagaan, sumber daya, dan jaringan. Sementara itu, peningkatan daya saing bangsa bermakna bahwa iptek dan pendidikan tinggi dapat memberikan kontribusi dalam penguatan perekonomian yang ditunjukkan oleh keunggulan produk teknologi hasil litbang yang dihasilkan oleh industri/perusahaan yang didukung oleh lembaga litbang (LPNK, LPK, badan usaha, dan perguruan tinggi) dan tenaga terampil pendidikan tinggi.

Strategi adalah sarana bersama dengan tujuan jangka panjang yang hendak dicapai. Strategi adalah aksi potensial yang membutuhkan keputusan manajemen puncak dan sumber daya perusahaan dalam jumlah besar (David: 2011, 18). Sedangkan menurut Ireland,et.al., (2013:4) strategi adalah seperangkat komintmen dan tindakan yang terintergrasi dan terkoordinasi yang dirancang untuk mengeksploitasi kompetensi inti dan mencapai keunggulan kompetitif. Menurut 
Wignaraja (2005) bahwa strategi dalam organisasi pembelajar (learning organization) merupakah strategi bagaimana organisasi tumbuh dan memiliki daya saing untuk memenangkan persaingan. Ada tiga perspektif dalam memenangkan persaingan, yaitu perspektif: (a) makro berkaitan dengan keseimbangan internal dan eksternal negara dan fokus pada manajemen nilai tukar yang riil, (b) strategi bisnis berkaitan dengan persaingan antara perusahaan dan negara yang memiliki peran berbeda dan terbatas untuk kebijakan publik, (c) teknologi dan inovasi yang menekankan pada inovasi dan pembelajaran yang menghasilkan nilai dan berdaya saing tinggi.

\section{METODE PENELITIAN}

Metode yang digunakan membahas masalah ini adalah deskriptif kualitatif dengan teknik pengumpulan data melalui: studi literature, partisipative observation dan wawancara dengan dengan pimpinan P3M PNJ yang memiliki kewenangan dan kebijakan dalam pelaksanaan tri dharma perguruan tinggi untuk kegiatan penelitian yang telah dilakukan dalam kurun waktu tiga tahun terakhir (2015-2017) di PNJ.

\section{HASIL DAN PEMBAHASAN}

Kegiatan penelitian yang dilakukan oleh dosen di PNJ dalam tiga tahun terakhir ini mengalami peningkatan jumlah dilihat dari sisi dosen mampu mendapatkan dana dan output penelitian terapan dan berdampak pada peningkatkan daya saing organisasi. Merujuk pada kriteria pengelompokkan lembaga/pusat/unit penelitian dan pengabdian kepada masyarakat dari Kemenristekdikti ada empat, yaitu: kelompok mandiri, utama, madya dan binaan. Pada tahun 2013 Pusat Penelitian dan Pengabdian kepada Masyarakat (P3M) PNJ masih berada pada kelompok madya akan tetapi dalam dua tahun terakhir ini P3M PNJ sudah naik ke klaster Utama sebagai bentuk hasil kinerja yang telah dilakukan dalam penelitian dan pengabdian kepada masyarakat yang melibatkan dosen dan mahasiswa. Penelitian yang dilakukan oleh dosen dan mahasiswa PNJ dilakukan sesuai dengan kompetensi dan dasar keilmuan yang dimiliki dan bersinergi dengan bidang kelompok keilmuan lain yang menunjang pemecahan dari masalah yang ada di masyarakat. Merujuk pada rencana strategis (Renstra) kinerja P3M PNJ tahun 2016-1019, paramater yang dinilai meliputi: (a) sumber daya penelitian, (b) manajemen penelitian, (c ) luaran penelitian, dan (d) revenue generating. Berikut pembahasan empat aspek penilaian kinerja penelitian yang telah dilaksanakan di PNJ untuk data tahun 2016, yaitu:

1. Aspek Sumber Daya

Aspek sumber daya manusia dalam kegiatan penelitian merupakan bagian penting dan modal dasar agar hasil penelitian berdampak secara ekonomi dan berpotensi paten. 
Tabel 1. Aspek Sumber Daya yang dinilai

\begin{tabular}{|c|c|c|c|}
\hline No & $\begin{array}{l}\text { Aspek } \\
\text { Dinilai }\end{array}$ & $\begin{array}{l}\text { Bentuk Rencana Dan } \\
\text { Hasil Yang Diinginkan }\end{array}$ & $\begin{array}{lll}\begin{array}{l}\text { Bentuk } \\
\text { dilakukan }\end{array} & \text { Strategi } & \text { yang } \\
\end{array}$ \\
\hline 1 & \multicolumn{3}{|c|}{ Sumber Daya Penelitian } \\
\hline & $\begin{array}{l}\text { A. Sumber daya } \\
\text { dosen: } \\
\text { 1) Dosen yang } \\
\text { terlibat kegiatan } \\
\text { penelitian } \\
\text { 2).Kualifikasi } \\
\text { pendidikan }\end{array}$ & $\begin{array}{l}\text { Dosen di PNJ terdiri dari } \\
\text { dosen PNS dan Non PNS. } \\
\text { Dosen diberikan hak yang } \\
\text { sama untuk melakukan } \\
\text { penelitian mengacu pada } \\
\text { aturan yang berlaku dari } \\
\text { pemerintah. Renstra P3M } \\
\text { untuk dosen yang aktif } \\
\text { meneliti diproyeksikan } \\
\text { tahun } 2016 \text { (322 orang) } \\
\text { dan } 2017 \text { (336 orang). } \\
\text { Sedangkan dosen pada } \\
\text { tahun } 2016 \text { bergelar S1 } \\
\text { tahun } 26 \text { orang, S2 (272 } \\
\text { orang), dan S3 (26 orang) } \\
\text { dan proyeksi dosen pada } \\
\text { tahun } 2017 \text { bergelar S1 } \\
\text { tahun } 20 \text { orang, S2 (286 } \\
\text { orang), dan S3 (30 orang). }\end{array}$ & $\begin{array}{lr}\text { Strategi dilakukan } & \begin{array}{r}\text { dengan } \\
\text { mempertimbangan }\end{array} \\
\text { pekuatan } \\
\text { pada jumlah dan kualifikasi } \\
\text { dosen yang dimiliki saat ini di } \\
\text { PNJ, serta memberikan peluang } \\
\text { dan kesempatan } r \\
\text { melakukan penelitian } \\
\text { memiliki yang } \\
\text { peningkatan orientasi } \\
\text { penelitian berbasis terapan, } \\
\text { berpotensi } 4 \text { HAKI } \\
\text { berdampak ekonomis. dan } \\
\text { Strategi ini menjadi bagian } \\
\text { dalam proses memenangkan } \\
\text { persaingan dan meningkatkan } \\
\text { kualitas penelitian PNJ. }\end{array}$ \\
\hline 2 & \multicolumn{3}{|c|}{ Sumber Dana Penelitian } \\
\hline & $\begin{array}{l}\text { 1) Dana BOPTN } \\
\text { DRPM (Hibah } \\
\text { kompetitif } \\
\text { nasional) }\end{array}$ & $\begin{array}{lr}\text { Proyeksi dosen } & \text { yang } \\
\text { mendapatkan } & \text { dana } \\
\text { penelitian pada tahun } 2016 \\
\text { ada } 36 \text { judul dan tahun } \\
2017 \text { ada } 40 \text { judul. }\end{array}$ & $\begin{array}{l}\text { Perlu dilakukan strategi yang } \\
\text { menunjang keberlanjutan } \\
\text { program kegiatan penelitian } \\
\text { dengan perolehan dana yang } \\
\text { berasal } \\
\text { DRPM/Simlitabmas/hibah } \\
\text { kompetitif sehingga kualitas } \\
\text { periset menjadi penting dalam } \\
\text { mendapatkan hibah ini. Jumlah } \\
\text { dosen yang mendapatkan hibah } \\
\text { dari Kemenristekdikti terus } \\
\text { bertambah. }\end{array}$ \\
\hline & $\begin{array}{l}\text { 2) Dana PNBP dan } \\
\text { lain-lain }\end{array}$ & $\begin{array}{ll}\text { Proyeksi dosen } & \text { yang } \\
\text { mendapatkan } & \text { dana } \\
\text { penelitian PNBP dan dana } \\
\text { lainnya pada tahun } 2016 \\
\text { ada } 115 \text { judul dan tahun } \\
2017 \text { ada } 120 \text { judul }\end{array}$ & $\begin{array}{l}\text { Perlu adanya strategi dan } \\
\text { kolaborasi dalam memperoleh } \\
\text { dana penelitian di luar hibah } \\
\text { kompetitif nasional, yaitu dana } \\
\text { yang berasal dari PNB atau dana } \\
\text { lainnya. Strategi yang dilakukan } \\
\text { adalah dengan menghitung } \\
\text { jumlah dosen dalam melakukan } \\
\text { penelitian dengan jumlah dana } \\
\text { yang diperoleh dosen sehingga } \\
\text { kualitas penelitian mampu } \\
\text { memberikan hasil terbaik dan } \\
\text { bernilai jual ekonomis. }\end{array}$ \\
\hline
\end{tabular}




\begin{tabular}{|c|c|c|c|}
\hline 3 & Peneliti Asing & Tidak ada & 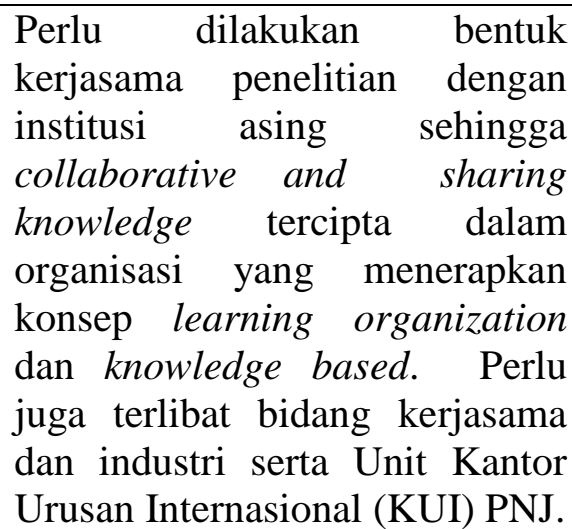 \\
\hline 4 & Staf Pendukung. & $\begin{array}{l}\text { Proyeksi staf pendukung } \\
\text { dalam membantu } \\
\text { kelancaran penelitian ada } \\
16 \text { orang pada tahun } 2016 \\
\text { dan berjumlah tetap } \\
\text { sampai tahun } 2019\end{array}$ & $\begin{array}{l}\text { Perlu diberikan pemahaman dan } \\
\text { pelatihan mengenai kegiatan } \\
\text { penelitian yang sudah online } \\
\text { mulai dari pengajuan peroposal } \\
\text { sampai monev hasil laporan } \\
\text { akhir penelitian, sehingga } \\
\text { kemampuan staf pendukung } \\
\text { akan memberikan kontribusi } \\
\text { penting terwujudnya lembaga } \\
\text { yang kredibel dan responsip } \\
\text { terhadap perubahan teknologi } \\
\text { informasi. }\end{array}$ \\
\hline 5 & $\begin{array}{l}\text { Unit Fasilitas } \\
\text { Penunjang. }\end{array}$ & $\begin{array}{l}\text { Proyeksi unit fasilitas } \\
\text { penunjang penelitian pada } \\
\text { tahun } 2016 \text { ada } 20 \text { unit dan } \\
\text { tahun } 2017 \text { ada } 26 \text { unit. }\end{array}$ & $\begin{array}{l}\text { Fasilitas penunjang dalam } \\
\text { membantu kelancaran penelitian } \\
\text { terus ditingkatkan sebagai upaya } \\
\text { ketersediaan fasilitas yang } \\
\text { memadai, terutama konektivitas } \\
\text { internet dengan pangkalan data } \\
\text { dikti. }\end{array}$ \\
\hline
\end{tabular}

Sumber: Renstra P3M-PNJ 2016, data diolah 2017

2. Aspek Manajemen Penelitian

Dalam aspek manajemen hasilnya adalah kegiatan yang dilakukan dalam penelitian harus mengacu pada SOP yang telah ditetapkan oleh lembaga Pusat
Penelitian dan Pengabdian kepada Masyarakat Politeknik Negeri Jakarta (PNJ). Berikut tabel mengenai penilaian aspek manajemen penelitian.

Tabel 2. Aspek Manajemen Penelitian

\begin{tabular}{|c|c|c|c|}
\hline No & \multicolumn{3}{|c|}{ Aspek Manajemen Penelitian } \\
\hline 1 & Kelembagaan & $\begin{array}{l}\text { Sudah ada perencanaan } \\
\text { mengenai perubahan nama dari } \\
\text { Pusat Penelitian dan Pengabdian } \\
\text { kepada Masyarakat (P3M) } \\
\text { menjadi Lembaga Penelitian dan } \\
\text { Pengabdian kepada Masyarakat } \\
\text { (LPPM) agar lembaga dapat } \\
\text { bergerak lebih cepat dalam } \\
\text { melaksanakan kegiatannya. }\end{array}$ & $\begin{array}{l}\text { Direalisasikan sesuai dengan } \\
\text { pagu anggaran yang } \\
\text { disediakan P3M PNJ } \\
\text { terutama dengan posisi P3M } \\
\text { PNJ di kelompok Utama yang } \\
\text { dapat mendorong } \\
\text { meningkatkanya dosen untuk } \\
\text { melakukan penelitian. }\end{array}$ \\
\hline
\end{tabular}




\begin{tabular}{|c|c|c|c|}
\hline 2 & $\begin{array}{l}\text { Standar Prosedur } \\
\text { (SOP) }\end{array}$ & $\begin{array}{l}\text { Sudah ada SOP terkait } \\
\text { penelitian dan bersinergi dengan } \\
\text { unit penjaminan mutu (SPMI) } \\
\text { sehingga kegiatan penelitian dan } \\
\text { monev di PNJ dilakukan sesuai } \\
\text { prosedur yang berlaku. }\end{array}$ & $\begin{array}{l}\text { Direalisasikan sesuai dengan } \\
\text { pagu anggaran yang } \\
\text { disediakan dan melekat pada } \\
\text { pagu anggaran P3M-PNJ. } \\
\text { Strategi yang } \\
\text { direkomendasikan adalah } \\
\text { strategi stabilitas. }\end{array}$ \\
\hline 3 & Forum Ilmiah & $\begin{array}{l}\text { Forum ilmiah yang dihadiri oleh } \\
\text { pimpinan P3M dan dosen } \\
\text { menjadi bagian penting dalam } \\
\text { upaya meningkatkan } \\
\text { kemampuan sert peringkat } \\
\text { kelembagaan sehingga memiliki } \\
\text { kinerja penelitian yang baik. } \\
\text { Forum ilmiah tidak hanya di } \\
\text { dalam negeri tetapi di luar } \\
\text { negeri dengan melibatkan dosen } \\
\text { sebagai peserta, pemakaah dan } \\
\text { pembicara kunci dalam forum } \\
\text { ilmiah tersebut. Jumlah dosen } \\
\text { yang diproyeksikan mengikuti } \\
\text { forum ilmiah pada tahun } 2016 \\
\text { ada } 11 \text { orang sedangkan tahun } \\
2017 \text { ada } 14 \text { orang. Faktanya } \\
\text { jumlah dosen yang terlibat } \\
\text { dalam forum ilmiah baik di } \\
\text { dalam negeri/luar negeri } \\
\text { melebihi rencana yang } \\
\text { diharapkan. }\end{array}$ & $\begin{array}{l}\text { Perlu adanya pembinaan dan } \\
\text { pemberian penghargaan dari } \\
\text { institusi PNJ bagi dosen yang } \\
\text { ikut serta dalam forum ilmiah } \\
\text { baik tingkat nasional maupun } \\
\text { internasional. Hal ini sesuai } \\
\text { dengan konsep learning } \\
\text { organization yang } \\
\text { memandang sumber daya } \\
\text { manusia sebagai modal atau } \\
\text { konsep human capitan asset } \\
\text { diadopsi oleh P3M PNJ } \\
\text { sehingga PNJ memiliki daya } \\
\text { saing tinggi. }\end{array}$ \\
\hline
\end{tabular}

3. Aspek Luaran Penelitian

Tabel 3. Aspek Luaran Kegiatan Penelitian

\begin{tabular}{|c|c|c|c|}
\hline No & $\begin{array}{l}\text { Aspek yang } \\
\text { dilakukan }\end{array}$ & $\begin{array}{l}\text { Bentuk Rencana dan Hasil } \\
\text { yang diinginkan }\end{array}$ & Strategi yang dilakukan \\
\hline 1 & $\begin{array}{l}\text { Publikasi di } \\
\text { Jurnal }\end{array}$ & $\begin{array}{lrr}\text { Untuk publikasi } & \text { hasil } \\
\text { penelitian yang dimuat dalam } \\
\text { jurnal nasional terakreditasi, } \\
\text { jurnal nasional tidak } \\
\text { terakreditasi, baik nasional, } \\
\text { jurnal internasional terindeks } \\
\text { scopus dan jurnal yang } \\
\text { memiliki high impact yang } \\
\text { tinggi, DOJ diproyeksikan } \\
\text { pada tahun 2016 berjumlah } 57 \\
\text { artikel dan } 2017 \text { berjunlah } 65 \\
\text { artikel. Faktanya jumlah } \\
\text { artikel yang dimuat dalam } \\
\text { jurnal nasional ridak } \\
\text { terakreditasi dapat dicapai }\end{array}$ & $\begin{array}{l}\text { Dilakukan penguatan pada dosen } \\
\text { yang melakukan penelitian untuk } \\
\text { menulis artikel ilmiah dan } \\
\text { diproyeksikan dimuat pada jurnal } \\
\text { terakreditasi baik nasional maupun } \\
\text { internasional. Untuk mencapai hal } \\
\text { tersebut, maka P3M membuat } \\
\text { strategi menyelenggarakan } \\
\text { pelatihan secara teratur setiap } \\
\text { tahun dan mengundang dosen } \\
\text { untuk mengikuti: } \\
\text { a.pelatihan penyusunan proposal } \\
\text { penelitian dan klinikal, } \\
\text { b.workshop penyusunan proposal } \\
\text { penelitian prioritas nasional dan }\end{array}$ \\
\hline
\end{tabular}




\begin{tabular}{|c|c|c|c|}
\hline & & $\begin{array}{l}\text { tetapi untuk jurnal rerindeks } \\
\text { scopus dan internasional } \\
\text { terakreditasi belum sesuai } \\
\text { dengan rencana. }\end{array}$ & $\begin{array}{l}\text { hibah kompetensi, } \\
\text { c.pelatihan metodologi penelitian, } \\
\text { d. workshop rujukan jurnal dalam } \\
\text { kajian pustaka. } \\
\text { Selain itu dilakukan kegiatan } \\
\text { seperti: Pelatihan Penulisan } \\
\text { Artikel Ilmiah, Pelatihan Penulisan } \\
\text { Artikel pada Jurnal Internasional. } \\
\text { Selanjutnya bagi dosen yang } \\
\text { artikelnya dimuat pada jurnal } \\
\text { terakreditasi nasional akan diberi } \\
\text { insentif sebesar Rp. 2.000.000, } \\
\text { sedangkan untuk jurnal } \\
\text { internasional insentifnya sebesar } \\
\text { Rp. } 5.000 .000 \text {. }\end{array}$ \\
\hline 2 & Pemakalah & $\begin{array}{l}\text { Dosen yang menjadi } \\
\text { pemakalah di tingkat nasional } \\
\text { dan internasional pada tahun } \\
2016 \text { direncanakan berjumlah } \\
115 \text { orang. Sedangkan tahun } \\
2017 \text { berjumlah } 125 \text { orang. }\end{array}$ & $\begin{array}{l}\text { Perlu adanya SOP yang mengatur } \\
\text { keterlibatan dosen dalam kegiatan } \\
\text { ilmiah sebagai pemakalah yang } \\
\text { diapresiasi oleh lembaga sebagai } \\
\text { nilai tambah bagi organisasi yang } \\
\text { menganut pada konsep knowledge } \\
\text { based dan learning organization, } \\
\text { sehingga mampu bersaing tidak } \\
\text { hanya di tingkat nasional tetapi } \\
\text { juga internasional. }\end{array}$ \\
\hline 3 & HKI & $\begin{array}{l}\text { Hasil luaran akhir dari } \\
\text { penelitian adalah HKI } \\
\text { diproyeksikan pada tahun } \\
2016 \text { berjumlah } 3 \text { buah dan } \\
2017 \text { berjumlah } 5 \text { buah HKI. }\end{array}$ & $\begin{array}{l}\text { a. Strategi dilakukan dengan } \\
\text { adanya pelatihan HKI dan potensi } \\
\text { Paten kepada peneliti secara rutin } \\
\text { oleh P3M PNJ baik dosen PNS } \\
\text { maupun Non PNS. } \\
\text { b. Membantu pengurusan } \\
\text { dokumen dosen yang mengajukan } \\
\text { HKI ke Dirjen HKI. }\end{array}$ \\
\hline 4 & Buku Ajar & $\begin{array}{l}\text { Hasil luaran akhir dari } \\
\text { penelitian adalah buku ajar } \\
\text { diproyeksikan pada tahun } \\
2016 \text { berjumlah } 20 \text { buah dan } \\
2017 \text { berjumlah } 25 \text { buah . } \\
\text { Pelatihan penyusunan buku } \\
\text { ajar selama ini menjadi ranah } \\
\text { kegiatan dari P3AI, akan } \\
\text { tetapi dari penelitian } \\
\text { diharapkan ada buku ajar } \\
\text { yang berfungsi untuk } \\
\text { meningkatkan kualitas } \\
\text { pembelajaran. }\end{array}$ & $\begin{array}{l}\text { a. Strategi harusnya dilakukan } \\
\text { secara sinergi antara kegiatan } \\
\text { P3AI dan P3M PNJ dalam } \\
\text { penulisan buku ajar hasil } \\
\text { penelitian sehingga buku ajar } \\
\text { tersebut mampu mendukung } \\
\text { kualitas pembelajaran. } \\
\text { b. Buku ajar hasil penelitian harus } \\
\text { memiliki ISBN. } \\
\text { c. Strategi yang direkomendasikan } \\
\text { adalah merujuk pada teori } \\
\text { mengenai strategi concentric } \\
\text { diversification, yaitu strategi } \\
\text { menambah produk dan jasa baru } \\
\text { akan tetapi keduanya masih saling }\end{array}$ \\
\hline
\end{tabular}




\begin{tabular}{|c|c|c|c|}
\hline & & & berhubungan. \\
\hline 5 & $\begin{array}{ll}\text { Luaran } & \text { Iptek } \\
\text { lainnya } & \end{array}$ & $\begin{array}{l}\text { Model dan prototype sudah } \\
\text { ada yang berpotensi dan } \\
\text { berdampak } \\
\text { pengembangan } \\
\text { masyarakat. }\end{array}$ & $\begin{array}{l}\text { Penelitian yang dilakukan dosen } \\
\text { dalam bidang rekayasa maupun } \\
\text { sosial humaniora difokuskan pada } \\
\text { keilmuan yang sesuai dengan } \\
\text { kompetensi dosen sehingga } \\
\text { memberikan dampak ekonomis } \\
\text { kepada masyarakatnya. }\end{array}$ \\
\hline
\end{tabular}

Sumber: Renstra P3M-PNJ 2016, data diolah 2017

4. Aspek Revenue Generating

Tabel 4. Aspek Revenue Generating

\begin{tabular}{|l|l|l|l|l|}
\hline No & \multicolumn{1}{|c|}{$\begin{array}{l}\text { Aspek Yang } \\
\text { dinilai }\end{array}$} & \multicolumn{1}{|c|}{ Hasil } & \multicolumn{2}{|l|}{ Strategi yang dilakukan } \\
\hline 1 & $\begin{array}{l}\text { Aspek Kontrak } \\
\text { Kegiatan }\end{array}$ & $\begin{array}{l}\text { Data non penelitian/kontrak } \\
\text { kerja diproyeksikan pada } \\
\text { tahun 2016 ada 4 buah } \\
\text { kontrak dan tahun 2017 ada } \\
\text { 6 buah }\end{array}$ & $\begin{array}{l}\text { Kontrak penelitian menjadi } \\
\text { rujukan dalam pelaksanaan } \\
\text { penelitian yang teratur dan } \\
\text { dilaksanakan sesuai SOP. }\end{array}$ \\
\hline 2 & Unit Bisnis & $\begin{array}{l}\text { Unit bisnis dari hasil } \\
\text { penelitian diharapkan pada } \\
\text { tahun 2016 ada 4 buah dan } \\
\text { tahun 2017 ada 5 buah unit } \\
\text { bisnis. }\end{array}$ & $\begin{array}{l}\text { Unit binis perlu dihidupkan } \\
\text { kembali seperti inkubator bisnis, } \\
\text { dan bentukpenelitian lainnya } \\
\text { yang berpotensi pada penciptaan } \\
\text { unit bisnis yang mampu } \\
\text { meningkatkan daya saing PNJ } \\
\text { dan memberikan keuntungan } \\
\text { kepada dosen tidak hanya } \\
\text { keilmuan tetapi juga sisi } \\
\text { bisnisnya. }\end{array}$ \\
& & & \\
& & &
\end{tabular}

Sumber: Renstra P3M-PNJ 2016, data diolah 2017

\section{KESIMPULAN DAN SARAN}

\section{Kesimpulan}

Kesimpulan yang dapat diberikan adalah:

1. Penelitian yang dilakukan oleh dosen PNJ telah memberikan dampak pada pola penelitian yang berpotensi pada HKI dan Paten yang berdampak secara ekonomis;

2. Pola kemitraan yang dibangun oleh PNJ dalam pelaksanaan penelitian sesuai aturan yang berlaku dari Kemenristekdikti dan standar yang dibuat SPM-PNJ;

3. Strategi keberlanjutan dan penguatan program yang dilakukan oleh PNJ dalam bidang penelitian menjadi isu penting dalam upaya meningkatkan daya saing organisasi.

\section{Saran}

1. Perlu pemetaan kekuatan kompetensi dari dosen dalam bidang keilmuannya masing-masing dalam upaya peningkatkan kualitas pelaksanaan penelitian sehingga memiliki nilai ekonomi yang tinggi;

2. Luaran hasil penelitian seperti buku ajar, artikel ilmiah yang dapat dimuat pada jurnal terakreditasi baik nasional maupun internasional perlu ditingkatkan agar memberikan kontribusi pada kinerja dan peringkat kelembagaan PNJ. 


\section{DAFTAR PUSTAKA}

David, Fred R. 2011. Manajemen Strategis Konsep. Terjemahan oleh Dono Sunardi dari Strategic Management. Jakarta : Salemba Empat

Carayannis, E.G,, Alexander, J, 1999. Winning by Co-opting in Strategic Government-University-Industry, R\&D Partnership, The Power of Complex, Dynamic Knowledge Networks, Journal of Technology Transfer, No. 24

Checkland \& Poulter, 2006. Learning for action. John Wiley \& Son. New York, USA

Hardjosoekarto, 2012. Soft System Methodology, UI Press, Jakarta

Hermans, Julie dan Annick Castiaux, 2007. Knowledge Creation Trough University-Industry Collaborative Research Projects, The Electronic Journal of Knowledge Management, Vol. 5 Issues No.1, pp: 43, www.ejkm.com

Laporan Penelitian dan Pengabdian Kepada Masyarakat, 2016. Pusat Penelitian dan Pengabdian pada Masyarakat, PNJ

Mariam, Iis, 2013. Penelitian Disertasi: Pemetaan Knowledge Creation pada Organisasi Politeknik Negeri Jakarta (Riset Tindakan Menggunakan Soft System Methodology), Dikti

Panduan Pelaksanaan Penelitian dan Pengabdian Kepada Masyarakat di Perguruan Tinggi, Edisi XI, Tahun 2017. Direktorat Riset dan Pengabdian Kepada Masyarakat, Direktorat Jenderal Penguatan Riset dan Pengembangan, Kementrian Riset, Teknologi, dan Pendidikan Tinggi.

Renstra P3M -PNJ, 2016

Wignaraja, Ganeshan, 2005. Competitiveness strategy in developing countries. A Manual for policy analysis, Routledge Studies in Developing economics, 
Iis Mariam dkk Tinjauan Kritis Kontribusi... 